\title{
ESTIMATION AND PREDICTION OF THE EFFECT OF ALTERNATIVE ENGINE TECHNOLOGIES AND POLICY MEASURES ON THE AIR QUALITY IN ST. PETERSBURG IN 2010-2030
}

\author{
Olga Lozhkina ${ }^{1,2}$, Vladimir Lozhkin², Leonidas Ntziachristos ${ }^{3}$ \\ ${ }^{1}$ Saint Petersburg University of State Fire Service of EMERCOM of Russia \\ Moskovskiy Prospekt, 149, Saint Petersburg, Russia \\ 2 Solomenko Institute of Transport Problems of the Russian Academy of Sciences \\ 12th Line of Vasilyevsky Island, 13, Saint Petersburg, Russia \\ ${ }^{3}$ School of Mechanical Engineering of the Aristotle University of Thessaloniki \\ PO Box 458, Thessaloniki, GR 541 24, Greece \\ 1olojkina@yandex.ru
}

\section{Abstract}

Problems related to the quality of life in big cities are increasingly relevant, especially with regard to environmental issues. Motor transport is responsible for pollutant emissions and noise that decisively affect life in modern cities. In this context, evaluating, monitoring and forecasting urban environmental quality in short-term and long-term perspective has become an important issue for decision making and planning of sustainable cities. Computational model COPERT was applied in the study to obtain long-term projections of road transport-related emission rates for pollutants and greenhouse gases.

Three scenarios for St. Petersburg considering the population size, vehicle fleet structure, travel behavior, and fuel consumption are developed. It is shown that the greatest effect in emission reduction can be achieved through modernization of the vehicle fleet. Additional environmental protection measures such as an increase in the share of alternative fuels and promotion of public transportation are expected to result in an additional decline of pollutants and GHG emissions by $7-20 \%$ and 5-7\%, respectively, in comparison with the Basic Scenario.

\section{Keywords}

Road transport, sustainable development, air pollution, short-term and long-term forecasting.

\section{Introduction}

Monitoring and improving air quality in built environment and cities are of crucial importance in the Russian Federation and all over the world (Franco et al., 2016; Genikhovich and Sciermeier, 1995; Genikhovich et al., 2002; Jain and Tiwari, 2016; Khreis et al., 2018; Lehtomäki et al., 2018; Lozhkin et al., 2013; Ni et al., 2018; Silva and Mendes, 2012; Singh et al., 2014; Taha, 2015; Zachariadis and Kouvaritakis, 2003; Yumino et al., 2015). Having ratified the Kyoto Protocol, the Convention on Long-Range Transboundary Air Pollution (CLRTAP) and other international acts, the Russian Federation confirmed its adherence to the concept of sustainable development and its intention to produce a considerable reduction in air pollutants and greenhouse gas (GHG) emissions.

Some progress has been achieved in reducing of vehicle-related air pollution through the application of strict Euro emission standards (Lozhkina and Lozhkin, 2015). However, we are still far from our objective to achieve such levels of air quality in big cities, like St. Petersburg, that do not exert a significant impact on the human health and the environment.

The results of our investigations (Lozhkina and Lozhkin, $2015,2016)$ as well as the official data of the Committee for Nature Use, Environmental Protection and Ecological Safety of the Government of St. Petersburg (The 
Committee on Environment Management, Environmental Protection and Ecological Safety of the Government of St. Petersburg, 1998, 2016) reveal that the city is periodically exposed to enhanced levels of nitrogen oxides (NOX), particulate matters (PM10 and PM2.5), carbon oxide (CO) and ozone (O3), and the road transport has been playing a key role in the air pollution of St. Petersburg since 1993, contributing to $75-85 \%$ of total pollutants and GHG emissions.

This is due to the continuous motorization that resulted in increasing the number of vehicles from 427,003 in 1993 to $1,063,500$ in 2003 and $1,982,843$ in 2013 (Report, 1998, 2016).

Real-time measurements and computational modeling represent complementary methods in air quality control and research. Air quality modeling enables not only realtime computational monitoring but also prediction and testing of future scenarios involving environmentallyfriendly technologies and policy measures in the transport sector. The aim of the present study was to estimate and predict the effect of alternative technologies and policy measures in road transport-related emissions reduction on the air quality in St. Petersburg in 2010-2030 using the COPERT modeling system.

\section{Methodology and input data collection}

The COPERT methodology and software were used in this study to estimate the effect of alternative engine technologies and policy measures on the air quality in St. Petersburg in short-term and long-term perspective up to 2030.

COPERT is a European tool to calculate emissions from road transport (Ntziachristos et al., 2009; Zachariadis and Samaras, 1999). It is a part of the EMEP/CORINAIR Atmospheric Emissions Inventory Guidebook used by EU member states for official air emission inventorying. COPERT is also widely used around the world in air quality studies and academic research (Fontaras et al., 2014; Franco et al., 2016; Lozhkina and Lozhkin, 2015, Ni et al., 2018).

The COPERT methodology has the following advantages allowing achieving the aim of the present study: emission factors for more than 450 individual vehicle types including present and future hybrid and Euro 6 vehicles; estimates for a wide range of pollutants and GHG, including $\mathrm{CO}$, NOX, volatile organic compounds (VOCs), particulate matter (PM), $\mathrm{NH}_{3}, \mathrm{CH}_{4}$ (calculated on the basis of vehicle emission factors), $\mathrm{CO}_{2}, \mathrm{SO}_{2}$ and heavy metals $\mathrm{Pb}, \mathrm{Cd}, \mathrm{Cr}, \mathrm{Cu}, \mathrm{Ni}, \mathrm{Zn}$, Se (estimated through the amount of fuel consumed). It also permits to analyze hot and cold emissions and emissions due to the evaporation of non-methane volatile organic compounds (NMVOCs).

Statistics on the vehicle fleet structure and vehicle age were gained from the Vehicle Market of Russia $(2010,2015$, 2017). Average values of annual vehicle mileage were determined based on driver polling. Average seasonal meteorological parameters for St. Petersburg were taken from the official site of the Russian Meteorological Service (www.meteorf.ru).

Taking into account that the Russian vehicle fleet differs from the European one due to a large use of national vehicle brands, we modified emission factors for some pollutants $\left(\mathrm{NO}_{x}, \mathrm{CO}, \mathrm{PM}_{10}\right)$ according to the Russian data.

Various scenarios of road transport development in St. Petersburg in long-term perspective up to $\mathbf{2 0 3 0}$

Current state of the road transport sector

The main gap in the activity data in the sector of motor transport is the lack of information on distribution of vehicles by emission technologies and absence of available statistics on fuel consumption.

Table 1 shows patterns in the vehicle fleet composition in St. Petersburg across a range of years.

Passenger cars have accounted for around four-fifths of all motor vehicles since 2004 and continue to be the main contributor to pollutants and GHG emissions.

The analysis of the data reveals that the passenger car fleet continued to grow more quickly than any other vehicle type, multiplying by a factor of 1.78 from 2003 to 2013. The peak was in 2013. In 2014-2015, the number of cars slightly fell, and then, in 2016, it began to increase again.

The fleet of HDV also saw the largest increase in 2013 and in 2017 (Table 1). The number of buses and coaches

Table 1. Vehicle fleet structure in St. Petersburg, 2004-2017.

\begin{tabular}{|l|l|l|l|l|l|l|l|}
\hline & 2004 & 2005 & 2006 & 2007 & 2008 & 2009 & 2010 \\
\hline $\begin{array}{l}\text { Passenger } \\
\text { cars }\end{array}$ & 980,800 & $1,013,600$ & $1,063,500$ & $1,165,600$ & $1,284,600$ & $1,388,800$ & $1,462,367$ \\
\hline Trucks & 104,841 & 106,170 & 114,663 & 121,731 & 122,458 & 117,231 & 129,043 \\
\hline Buses & 18,735 & 19,550 & 21,792 & 23,757 & 22,400 & 22,030 & 22,714 \\
\hline Total & $1,104,376$ & $1,139,320$ & $2,231,955$ & $1,311,088$ & $1,429,458$ & $1,528,061$ & $1,614,124$ \\
\hline & 2011 & 2012 & 2013 & 2014 & 2015 & 2016 & 2017 \\
\hline $\begin{array}{l}\text { Passenger } \\
\text { cars }\end{array}$ & $1,525,967$ & $1,537,437$ & $1,741,867$ & $1,670,794$ & $1,638,183$ & $1,676,379$ & $1,710,811$ \\
\hline Trucks & 138,967 & 201,033 & 220,067 & 207,975 & 217,738 & 214,003 & 223,662 \\
\hline Buses & 20,965 & 22,449 & 21,513 & 22,054 & 20,221 & 19,659 & 29,843 \\
\hline Total & $1,685,899$ & $1,760,919$ & $1,983,447$ & $1,900,823$ & $1,876,142$ & $1,910,041$ & $1,964,316$ \\
\hline
\end{tabular}


was more or less the same across 2004-2016 and sharply grew by 1.5 times in 2017.

\section{Analysis of national plans for transport development}

In the field of reducing motor transport-related air pollution, several legislative and technological measures were implemented nationwide. In 2003, the Federal Law on Banning Production and Use of Leaded Gasoline in the Russian Federation entered into force. In 2005, a direct step-by-step introduction of EU Vehicle Emission Standards was initiated, namely, the application of Directive 98/69/EC of the European Parliament and of the Council of 13 October 1998 was approved by the Russian Federation Government Decree No. 609 dated 12.10.2005 concerning Requirements to Harmful Emissions from Vehicles Produced in the Russian Federation.

Then, in 2008, technical regulations "Requirements to Automobile and Aviation Gasoline, Diesel and Ship Fuel, Jen Engine Fuel and Furnace Boiler Oil", harmonized with Directives 98/70/EC, 2005/55/EC and also aimed at the reduction of the transport's damaging effect on air quality, were introduced.

The implementation schedule of emission and fuel Standards in the Russian Federation is presented in Table 2.

Table 2. Implementation schedule of the emission and fuel standards in the Russian Federation.

\begin{tabular}{|l|l|l|l|}
\hline \multicolumn{2}{|l|}{ Emission standards } & \multicolumn{2}{l|}{ Fuel standards } \\
\hline Euro 2 & 2005 & Euro 2 & 2005 \\
\hline Euro 3 & 2010 & Euro 3 & 2013 \\
\hline Euro 4 & 2013 & Euro 4 & 2015 \\
\hline Euro 5 & 2015 & Euro 5 & 2016 \\
\hline
\end{tabular}

In 2008, the Transport Strategy of the Russian Federation up to 2030 was approved by the Government of the Russian Federation. One of its priority goals is to reduce the harmful impact of transport on the environment by 2030 by increasing the use of alternative fuels and expanding the vehicle fleet with hybrid, electric and hydrogen vehicles.
Scenarios of motor transport development: assumptions and reasons behind their selection

This section provides an overview of some of the key factors that explain assumptions and reasons behind scenario development.

Over the last years, there has been a steady growth in population of St. Petersburg from 4,899,000 inhabitants in 2010 to $5,282,000$ inhabitants in 2016 . We suppose that it will continue to grow in the future.

Since motor transport is the main means for people and goods transportation in the city, we assume that the fleet will generally tend to increase by 2030 , even though some fluctuations in road traffic levels may occur because of changes in the economy (including GDP) and disposable incomes of people, affecting car ownership and travel behavior of car owners. Table 3 presents actual and projected increase in the number of vehicles in St. Petersburg in 2010-2030.

The projections presume the assumptions around the current rates of economic and population growth, take-up of certain technologies and impacts of current government policies will remain valid.

The projections do not attempt to account for inevitable, but as yet unknown, changes that will occur in technology, energy demand and supply, and the international and domestic economy. The main assumption of all scenarios is progress in reducing pollutants and GHG emissions from motor vehicles in 2010-2030 through technological and fuel measures and through the growth of public transportation.

The main considerations are as follows: growth of the vehicle fleet (Table 3), modernization of the vehicle fleet over the projected period according to the implementation schedule of emission and fuel standards in the Russian Federation (Table 2).

The following three scenarios were developed by the authors:

1) Basic Scenario (Business-as Usual scenario): implementation of the main considerations listed above with the share of alternative fuels about $1.5-3 \%$.

2) Scenario 2 (Bio scenario) considering all assumptions of the Basic Scenario and some additional

Table 3. Actual and projected increase in the number of vehicles in St. Petersburg in short-term and long-term perspective.

\begin{tabular}{|l|l|l|l|l|l|}
\hline & 2010 & 2015 & 2020 & 2025 & 2030 \\
\hline Passenger cars & $1,470,490$ & $1,850,000$ & $1,950,000$ & $2,100,000$ & $2,250,000$ \\
\hline Trucks & 126,531 & 160,000 & 210,000 & 220,000 & 220,000 \\
\hline Buses & 21,525 & 22,000 & 24,000 & 24,000 & 24,000 \\
\hline Total & $1,618,546$ & $2,032,000$ & $2,454,000$ & $2,619,000$ & $2,834,000$ \\
\hline
\end{tabular}

Table 4. Main indicators of Scenario 2, developed considering the National Transport Strategy.

\begin{tabular}{|l|l|l|l|l|l|l|l|}
\hline & 2010 & 2011 & 2015 & 2018 & 2020 & 2024 & 2030 \\
\hline Share of alternative fuels, \% & 3 & 4 & 9 & 14 & 20 & 26 & 30 \\
\hline $\begin{array}{l}\text { Share of vehicles with hybrid, electric } \\
\text { and hydrogen engines }\end{array}$ & $<1$ & $<1$ & 16 & 24 & 29 & 39 & 54 \\
\hline
\end{tabular}


measures proposed in the Transport Strategy of the Russian Federation up to 2030 (Table 4).

3) Scenario 3 (Public Transportation + Fleet Modernization scenario): Basic Scenario plus an increase in the share of public transportation by $5 \%$ in $2015,7 \%$ in 2020, $9 \%$ in 2025 and $12 \%$ in 2030 in respect to the Basic Scenario. The forecast starts from the base year of 2010 and projects emission rates of major pollutants and $\mathrm{GHG}$ for every 5 years up to 2030 .

\section{Results and discussion}

The results of the numerical investigations show that we may expect a decline in the exhaust emissions from road transport by 2030 . With the projected increase in the number of vehicles by a factor of 1.75 by 2030 compared to the base year of 2010, the greatest environmental effect could be achieved through faster introduction of stricter Euro 4-Euro 5 emission standards and stricter Euro 4Euro 5 fuel quality standards (Basic Scenario).

The modeled trends show the reduction of greenhouse gas emissions $\left(\mathrm{N}_{2} \mathrm{O}\right.$ by a factor of 9 and $\mathrm{CH}_{4}$ by a factor of 1.2-1.5) and the reduction of pollutant emissions ( $\mathrm{CO}$ by a factor of 3, VOC and NMVOC by a factor of $2, \mathrm{NH}_{3}$ by a factor of $1.4, \mathrm{PM}$ by a factor of 2 . The $\mathrm{NO}_{\mathrm{x}}$ emissions rate is expected to remain at the same level.

A continuous increase in the share of passenger cars and buses operating on compressed natural gas (CNG) and biodiesel by $30 \%$ by 2030 , as indicated in the National Transport Strategy (Scenario 2), could lead to the reduction of greenhouse gas emissions, namely, $\mathrm{CO}_{2}$ by $11 \%$ and $\mathrm{N}_{2} \mathrm{O}$ by $12 \%$. As to pollutants, their emissions are expected to be reduced by $7.6 \%$ in respect to $\mathrm{CO}$, by $1.8 \%$ in respect to $\mathrm{NO}_{x}$, by $20 \%$ in respect to VOCs, and they are also expected to grow for $\mathrm{NH}_{3}$ and $\mathrm{CH}_{4}$ by 3 and $4 \%$, respectively, in comparison with 2030 in the Basic Scenario.
The use of diesel fuel corresponding to the Euro 5 quality standard would reduce $\mathrm{SO}_{2}$ emissions by a factor of 2-2.5 in 2030 compared to the base year of 2010 (Scenarios 1-3).

Emissions of heavy metals $\mathrm{Pb}, \mathrm{Cd}, \mathrm{Cu}, \mathrm{Cr}, \mathrm{Ni}$, Se $\mathrm{Zn}$, as calculated by COPERT, would increase approximately by a factor of 1.5-2 between 2010 and 2030 .

\section{Conclusions}

In recent twenty years, the number of motorized vehicles in St. Petersburg has risen sharply, but, thanks to some legislative and technological measures as well as to the increase of the purchasing capacity, there was considerable vehicle fleet modernization in the city over the last five years that resulted in the improvement of air quality.

The results of the numerical investigations also confirm this positive trend and show that a remarkable environmental effect could be achieved through faster modernization of the fleet with vehicles corresponding to Euro 4-Euro 6 emission standards and promotion of highquality fuels.

Additional environmental protection measures such as an increase in the share of alternative fuels and promotion of public transportation are expected to result in an additional decline of pollutants and $\mathrm{GHG}$ emissions by $7-20 \%$ and $5-7 \%$, respectively, in comparison with the Basic Scenario. It is evident that uncertainties are significant in long-term perspective. However, it is notable that, despite these uncertainties, our main conclusions are robust.

\section{Acknowledgements}

The study was carried out as a part of the project "Air Quality Governance in the ENPI East Countries" in 20112014, funded by the European Union. 


\section{References}

Analytical Agency “Avtostat” (2011). Vehicle Market of Russia in 2010, p.208. (in Russian)

Analytical Agency “Avtostat” (2016). Vehicle Market of Russia in 2015, p. 256 (in Russian)

Fontaras, G., Franco, V., Dilara, P. et al. (2014). Development and review of Euro 5 passenger car emission factors based on experimental results over various driving cycles. Sci Total Environ., 15, pp. 468-469. DOI: 10.1016/j.scitotenv.2013.09.043.

Franco, V., Zacharopoulou, T., Hammer, J. et al. (2016). Evaluation of Exhaust Emissions from Three Diesel-Hybrid Cars and Simulation of After-Treatment Systems for Ultralow Real-World NO Emissions. Environ Sci Technol., 50 (23), pp. 13151-13159. DOI: 10.1021/acs.est.6b03585.

Genikhovich, E.L., Gracheva, I.G., Onikul, R.I., Filatova, E.N. (2002). Air pollution modeling at urban scale - Russian experience and problems. Water, Air \& Soil Pollution: Focus, 2 (5-6), pp. 501-512. DOI: 10.1088/1742-6596/772/1/012031.

Genikhovich, E.L., Sciermeier, F.A. (1995). Comparison of United States and Russian complex terrain diffusion models developed for regulatory applications. Atmos. Environ., 29 (17), pp. 2375-2385. DOI: 10.1016/1352-2310(95)00053-2.

Jain, D., Tiwari, G. (2016). How would the present have looked like? Impact of non-motorized transport and public transport infrastructure on travel behavior, energy consumption and $\mathrm{CO}_{2}$ emissions. Sust. Cities and Society, 22, pp. 1-10. DOI: 10.1016/j. scs.2016.01.001.

Khreis, H., de Hoogh, K., Nieuwenhuijsen, M.J. (2018). Full-chain health impact assessment of traffic-related air pollution and childhood asthma. Environ Int., 114, pp. 365-375. DOI: 10.1016/j.envint.2018.03.008.

Klein, T., Kukkonen, J., Baklanov, A. et al. (2012). Interactions of physical, chemical, and biological weather calling for an integrated approach to assessment, forecasting, and communication of air quality. Ambio, 41 (8), pp. 851-864. DOI: 10.1007/ s13280-012-0288-z.

Lehtomäki, H., Korhonen, A., et al. (2018). Health Impacts of Ambient Air Pollution in Finland. Int J Environ Res Public Health., 15 (4). DOI: 10.3390/ijerph15040736.

Lozhkin, V.N., Lozhkina, O.V., Ushakov, A. (2013). Using K-Theory in Geographic Information Investigations of Critical-Level Pollution of Atmosphere in the Vicinity of Motor Roads. World Applied Sciences Journal, 23 (13), pp. 96-100.

Lozhkina, O.V., Lozhkin V.N. (2015). Estimation of road Transport related air Pollution in Saint Petersburg using European and Russian calculation Models. Transport. Res. Part D, 36, pp. 178-189. DOI: 10.1016/j.trd.2015.02.013.

Lozhkina, O.V., Lozhkin, V.N. (2016). Estimation of nitrogen oxides emissions from petrol and diesel passenger cars by means of on-board monitoring: Effect of vehicle speed, vehicle technology, engine type on emission rates. Transport. Res. Part $D$, 47, pp. 251-264. DOI: 10.1016/j.trd.2016.06.008.

$\mathrm{Ni}$, Z.Z., Luo, K. et al. (2018). Assessment of winter air pollution episodes using long-range transport modeling in Hangzhou, China, during World Internet Conference, 2015. Environ Pollut., 236, pp. 550-561. DOI: 10.1016/j.envpol.2018.01.069.

Ntziachristos, L., Gkatzoflias, D., Kouridis, Ch., Samaras Z. (2009). COPERT: A European Road Transport Emission Inventory Model. In: Proceedings of the 4th International ICSC Symposium on Information Technologies in Environmental Engineering, pp. 491-504. DOI: 10.1007/978-3-540-88351-7_37.

Silva, L.T., Mendes, J.F.G. (2012). City Noise-Air: An environmental quality index for cities (Review). Sust. Cities and Society, 4 (1), pp. 1-11. DOI: 10.1016/j.scs.2012.03.001.

Singh, V., Sokhi, R.S., Kukkonen, J. (2014). PM2.5 concentrations in London for 2008 - a modeling analysis of contributions from road traffic. J Air Waste Manag Assoc., 64 (5), pp. 509-518. DOI: 10.1080/10962247.2013.848244.

The Committee on Environment Management, Environmental Protection and Ecological Safety of the Government of St. Petersburg (1998). Report on Environmental situation in St. Petersburg and Leningrad Region in 1997. (Leningrad: Lencomecologhia) (in Russian)

The Committee on Environment Management, Environmental Protection and Ecological Safety of the Government of St. Petersburg (2016). Report on Environmental situation in St. Petersburg in 2015. Available at: http://www.infoeco.ru/assets/files/Doklad/ doklad_2015.pdf (accessed on 15.02.2018) (in Russian)

Taha, H. (2015). Meteorological, air-quality, and emission-equivalence impacts of urban heat island control in California. Sust. Cities and Society, 19, pp. 207-221. DOI: 10.1016/j.scs.2015.03.009.

Yumino, S., Uchida, T., et al. (2015). Total assessment for various environmentally conscious techniques from three perspectives: Mitigation of global warming, mitigation of UHIs, and adaptation to urban warming. Sust. Cities and Society, 19, pp. 236-249. DOI: 10.1016/j.scs.2015.05.010.

Zachariadis, T., Kouvaritakis, N. (2003). Long-term outlook of energy use and CO2 emissions from transport in Central and Eastern Europe. Energy Policy, 31 (8), pp. 759-773. DOI: 10.1016/S0301-4215(02)00126-X.

Zachariadis, T., Samaras, Z. (1999). An Integrated Modeling System for the Estimation of Motor Vehicle Emissions. J Air Waste Manag Assoc., 49 (9), pp. 1010-1026. DOI: 10.1080/10473289.1999.10463892. 